\title{
A REVIEW ON CARDIAC REMODELLING
}

\author{
VishwadeepakKimothi ${ }^{1}$, Rahul Singh Dhariyal ${ }^{2}$, Sanjay Singh ${ }^{3}$ \\ ${ }^{1,2,3}$ Siddhartha Institute of Pharmacy, Near IT Park, Dehradun-248001,Uttarakhand, India
}

Received: 02 April,2019

Accepted:09 May,2019

*Correspondence to:

\section{VishwadeepakKimothi}

Email:

vishwadeepakkimothi@gmail.com

Copyright: () the author(s), publisher and licensee Indian Academy of Pharmacists. This is an open-access article distributed under the terms of the Creative Commons Attribution Non-Commercial License, which permits unrestricted non-commercial use, distribution, and reproduction in any medium, provided the original work is properly cited.

Published by: OZZIE Publishers

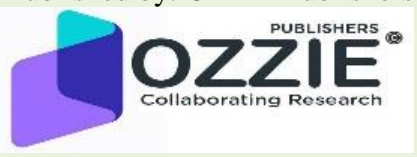

\section{Abstract}

Heart failure (HF) is a worldwide health problem that affects approximately 26 million individuals. It is known that heart disease progresses to $\mathrm{HF}$, and there is a link between cardiac remodelling and the development of HF. The term "remodelling" was used for the first time in 1982 by Hockman and Buckey, in a myocardial infarction (MI) model. Cardiac remodelling refers to changes in the size, shape, structure, and function of the heart. This can happen as a result of exercise (physiological remodeling) or after injury to the heart muscle (pathological remodeling).\{3\} The injury is typically due to myocardial infarction. Chronic hypertension, congenital heart disease with intracardiac shunting, and valvular heart disease may also lead to remodelling. Between the physiological and pathological remodelling, the physiological remodelling is reversible and the pathological remodeling is irreversible. Cardiac remodelling is considered to be not only an adaptive event but also a maladaptive phenomenon. In the acute phase of a myocardial stress, cardiac remodelling acts as an adaptive response that enables the heart to maintain cardiac output; however, after the prolonged stressful stimulus, this continuous process leads to progressive decompensation. The cardiac myocyte is the major cell involved in remodeling. Fibroblasts, collagen, the interstitium, and the coronary vessels to a lesser extent, also play a role. The most used methods to detect these changes are echocardiography, ventriculography, and nuclear magnetic resonance. Several markers may indicate a remodelling process, including changes in the expression of myosin heavy chain isoforms, with an increase in alpha- and a decrease in beta-myosin heavy chain, increased expression of GLUT-1, alpha-actin, natriuretic peptide, galectin, caveolin, neuronal nitric oxide synthase, angiotensin-converting enzyme, a decrease in GLUT-4, SERCA2a, and a shift from glucose to fatty acid oxidation.Medications may attenuate remodelling , Angiotensin-converting enzyme (ACE) inhibitors, Beta blockers (Carvedilol), may actually reverse the remodelling process by reducing left ventricular volumes and improving systolic function.

Keywords: Cardiac remodelling, Heart failure, Angiotensin -converting enzyme, Cardiac output, Chronic hypertension.

\section{INTRODUCTION}

The term "remodeling" was used for the first time in 1982 by Hockman and Buckey, in a myocardial infarction (MI) model. ${ }^{\{1\}}$ In cardiology, ventricular remodeling (or cardiac remodeling $)^{\{2\}}$ refers to changes in the size, shape, structure, and function of the heart. This can happen as a result of exercise (physiological remodeling) or after injury to the heart muscle (pathological remodeling). ${ }^{\{3\}}$ The injury is typically due to myocardial infarction. Chronic hypertension, congenital heart disease with intracardiac shunting, and valvular heart disease may also lead to remodeling. Between the physiological and pathological remodeling, the physiological remodeling is reversible and the pathological remodeling is irreversible. ${ }^{\{4,5,6\}}$. Cardiac remodeling is generally accepted as a determinant as a clinical course of heart failure(HF).Defined as genome expression resulting in molecular, cellular and interstitial changes and manifested clinically change in size, shape or function of the heart resulting from cardiac load or injury, cardiac remodeling is influenced by hemodynamic load, Neuro hormonal activation and other factors still under investigation. ${ }^{\text {[7] }}$ Cardiac remodeling is considered to be not only an adaptive event but also a maladaptive phenomenon. In the acute phase of a myocardial stress, cardiac remodeling acts as an adaptive response that enables the heart to maintain cardiac output; however, after the prolonged stressful stimulus, this continuous process leads to progressive decompensation. ${ }^{\{8\}}$ As a result of this phenomenon, the heart develops cellular changes such as myocyte hypertrophy ${ }^{\{9\}}$, necrosis ${ }^{\{10\}}$, apoptosis ${ }^{\{11,12\}}$, fibroblast proliferation ${ }^{\{13\}}$, increased fibrillarcollagen ${ }^{\{14\}}$ and fibrosis ${ }^{\{15\}}$.Cardiac remodeling may include ventricular hypertrophy, ventricular dilation, cardiomegaly, and other changes. The myocytes is the major cardiac cell involved in the remodeling process. ${ }^{\{16\}}$ Patients with major remodeling demonstrate progressive worsening of cardiac function, and it may underlie sizeable proportion of cardiovascular morbidity and mortality. ${ }^{\{17\}}$ 


\section{EPIDEMIOLOGY}

Heart failure (HF) is a worldwide health problem that affects approximately 26 million individuals. It is known that heart disease progresses to $\mathrm{HF}$, and there is a link between cardiac remodeling and the development of HF ${ }^{\{18\}}$ The burden of heart failure(HF) represent the inability of the heart to respond to circulatory demand of the organism. The main causes of HF are hypertension ischemic and valvular injuries whereas toxic, metabolic or genetic origins are less common. The prevalence of the HF is important and to more then 20 million people worldwide are estimated to suffer from HF. In the united kingdom, Stewart have an estimated that the annual direct cost of the HF in year 2000 about $1.9 \%$ of total expenditure of the national health service. ${ }^{\{19,20]}$

\section{Pathophysiology}

- The cardiac myocyte is the major cell involved in remodeling. Fibroblasts, collagen, the interstitium, and the coronary vessels to a lesser extent, also play a role. The remodeling process frequently include increase myocardial mass. The heart can respond to environment stimuli by growth or shrinkage with a dynamic range of the least 100 percent. Myocardial hypertrophy is the most properly defined increase cardio myocyte size which might be occur with or without the increase in overall myocardial mass; however term hypertrophy also been used to donate increased myocardial mass and wall thickness. ${ }^{\{21,22\}}$

- Physiologic remodeling is compensatory change in dimensions and function of the heart in the response physiologic stimuli such exercise and pregnancy. This type of the remodeling seen in athletes and has been called athletes heart. The pathologic remodeling may occurs with pressure overload, volume overload and other cardiac injury. ${ }^{\{23\}}$

\section{CLINICAL CHARACTERIZATION}

The clinical diagnosis of remodeling is based on the detection of morphological changes - changes in the cavity diameter, mass (hypertrophy and atrophy), geometry (heart wall thickness and shape), areas of scar after MI, fibrosis and inflammatory infiltrate (e.g in myocardititis). ${ }^{\{2\}}$ The most used methods to detect these changes are echocardiography, ventriculography, and nuclear magnetic resonance. $^{\{25\}}$ One example of clinical detection of remodeling occurs in the acute and chronic phase of MI. Another diagnostic method, still not used in routine clinical practice, consists of the detection of cell markers, which is based on the fact that cardiac remodeling involves the re expression of fetal genes. Several markers may indicate a remodeling process, including changes in the expression of myosin heavy chain isoforms, with an increase in alpha- and a decrease in beta-myosin heavy chain, increased expression of GLUT-1, alpha-actin, natriuretic peptide, galectin, caveolin, neuronal nitric oxide synthase, angiotensinconverting enzyme, a decrease in GLUT-4, SERCA2a, and a shift from glucose to fatty acid oxidation. ${ }^{\{26,28\}}$

\section{FUNTIONAL CHANGES ASSOCIATED WITH} CARDIAC REMODELLING

- Left ventricular enlargement in patients with anterior myocardial infraction. Marked increase in a volume results from increased circumference and the sphericity.

- Gross changes to the heart: As the heart remodel, geometry change; it becomes less elliptical and more spherical. There are also changes ventricular mass, compositions and volume; all of that may adversely affect cardiac function. ${ }^{\{29\}}$

- Cellular and molecular changes in the remodeling: remodeling included the cellular changes like myocyte hypertrophy, necrosis ,apoptosis, fibrosis, increased febrile collagen and fibroblast proliferation. ${ }^{\{30\}}$

\section{INFLUENCES ON CARDIAC REMODELING}

Changes in Hemodynamic Load:

Studies of global LV chamber volumes and muscle mass show that early LV dilation in patients with anterior wall MI may continue progressively and unabated; global compensatory (reactive) ventricular hypertrophy appears to be a delayed and limited adaptation during the first year. ${ }^{\{31\}}$ As a result of progressive ventricular dilation and insufficient development of reactive ventricular hypertrophy, global LV wall tension and stresses increase considerably during this period. ${ }^{\{32\}}$ The importance of remodeling as a pathogenic mechanism is unclear, and the factors leading to remodeling may be the major determinants of HF prognosis rather than ventricular dilation itself. If cardiac dilation persists without hypertrophy, myocardial wall stress is increased. A number of mechanisms may be stimulated by increased wall stress, and this may lead to further dilation of the heart. Without therapy to reduce ventricular dilation, decrease wall stress and promote a favorable neurohormonal pattern, this process progresses towards overt chronic HF. ${ }^{\{33\}}$

\section{Neurohormonal Activation in $\mathrm{HF}$ :}

- Neurohormonal activation in HF is known to mediate compensatory changes in response to falling cardiac output, but it is also a major component of disease progression and of the remodeling process. ${ }^{\{34,35-39\}}$

- Plasma norepinephrine levels, reflecting increased adrenergic activation, are elevated in $\mathrm{HF}$ patients ${ }^{\{40,41\}}$ and relate to prognosis. ${ }^{42\}}$ Higher levels of circulating plasma norepinephrine correlate with a poorer long-term prognosis. ${ }^{\{43,44,45\}}$ Increased plasma or tissue levels of other neurohormones also occur in patients with LV dysfunction and in asymptomatic patients post-MI without $\mathrm{HF}$, with activation increasing further as overt HF ensues. ${ }^{\{4\}}$ Most recently, neurohormonal activation was shown to decrease progressively post-MI in patients with a good prognosis. $\{47\}$

- Using measures of atrial natriuretic peptide (ANP), aldosterone, norepinephrine and plasma renin, asymptomatic patients who experienced an event within three months of MI had markedly elevated neurohormonal levels a mean of 10 days after infarction. ${ }^{\{47\}}$ In contrast, post-MI patients who were without cardiovascular events during the 38-month mean follow-up of the study had lower neurohormonal levels that decreased further over time. ${ }^{\{4\}}$

- In cell culture, angiotensin II increases DNA synthesis in myocardial fibroblasts and increases protein synthesis in both fibroblasts and myocytes. ${ }^{\{4\}}$ It appears to be an important mediator of the cellular 
responses to stretch, with local production resulting in proliferation and growth. ${ }^{\{49\}}$ Angiotensin II also increases coronary artery permeability, allowing diffusion of growth factors into the myocardial interstitium. ${ }^{\{50\}}$ It is known to cause necrosis and fibrosis through its cytotoxic effect on cardiac myocytes. ${ }^{\{51\}}$ Increased aldosterone production as a result of increased angiotensin II has hemodynamic consequences and stimulates collagen synthesis by myocardial fibroblasts. ${ }^{\{52\}}$ Increased aldosterone levels may also play a role in myocyte death through their effect on electrolyte balance. ${ }^{\{52\}}$

\section{Additional Factors that Influence Remodeling}

- The effects on remodeling of factors other than those related specifically to the renin angiotensin system (RAS) and the sympathetic nervous system (SNS) are currently under investigation and include endothelin, cytokines (tumor necrosis factors [TNF] and interleukins) and nitric oxide (NO) production and oxidative stress.

- Endothelins are potent vasoconstrictor peptides, the levels of which are known to be elevated in HF. ${ }^{\{3\}}$ Endothelin blockade has been shown to be beneficial in animal models and patients with HF. ${ }^{\{41,54\}}$

- $\quad$ Cytokines are proteins secreted by cells in response to a variety of stimuli including environmental stress. Circulating levels of the cytokine TNF-alpha are known to be raised in cachectic patients with chronic HF. This elevation has been associated with the marked activation of the RAS seen in patients with end stage disease. ${ }^{\{55,56\}}$ Data from the Studies of Left Ventricular Dysfunction (SOLVD) indicated that proinflammatory cytokines increase in patients as their functional HF classification deteriorates. ${ }^{[57]}$ Data have also shown that stimulation with pathophysiologic concentrations of TNF-alpha provokes a timedependent increase in $\mathrm{LV}$ remodeling in animal models of HF. ${ }^{\{58\}}$

- Oxidative stress is the term used to describe an imbalance between production of oxygen free radicals and antioxidant defenses, ${ }^{\{59\}}$ the importance of which is increasingly emerging with respect to $\mathrm{LV}$ dysfunction and HF progressionreviewed by Ferrari, et al. ${ }^{\{5\}}$ Cell viability depends on a complex interaction of inducers and suppressors of apoptosis, which are susceptible to modulation by cytokines such as TNFalpha. ${ }^{\{60\}}$ Cytokines indirectly increase apoptosis through their effect on the death domain within the cytoplasmic portion of the TNF receptor-1. They also exert a direct cytotoxic effect leading to necrosis. Both apoptosis and necrosis cause further deterioration in the composition and function of the ventricle. ${ }^{[59,, 61,62\}}$

\section{The Main Component of Cardiac Remodeling}

Cardiac Myocytes: Myocytes and other cardiac cell types are believed to be fundamentally involved in the remodeling process. Of all cardiovascular wall components, myocytes have received much attention in view of their contractile activity and numeric contribution to heart mass. As the result of an insult, myocyte numbers decrease and surviving myocytes become elongated or hypertrophied as part of an initial compensatory process to maintain stroke volume after the loss of contractile tissue. The thickness of the ventricular wall also increases. ${ }^{[63\}}$ Altered loading conditions stretch cell membranes and may play a role in inducing the expression of hypertrophy-associated genes. In cardiac myocytes, this may lead to the synthesis of new contractile proteins and the assembly of new sarcomeres. It is thought that the pattern in which these are laid down determines whether the cardiac myocytes elongate or increase their diameter. ${ }^{\{64\}}$ Increased wall stress may precipitate energy imbalance and ischemia, which is one of the major determinants of myocardial oxygen demand. This is thought to lead to a vicious cycle of increased wall stress and wall thickness and further energy imbalance and ischemia. ${ }^{\{65\}}$

The Role of Fibroblast Proliferation: Both fibroblasts and endothelial cells are activated in response to an ischemic insult. In human and animal models, fibroblast stimulation increases collagen synthesis and causes fibrosis of both the infarcted and noninfarcted regions of the ventricle, thus contributing to remodeling. ${ }^{\{66,67\}}$ The relative contribution of the interstitium to the remodeling process is, however, not clear.

The Role of Collagen Degradation: The myocardium consists of myocytes tethered and supported by a connective tissue network composed largely of fibrillar collagen, which is synthesized and degraded by interstitial fibroblasts. Myocardial collagenase is thought to be an important proenzyme present in the inactive form in the ventricle. ${ }^{\{68,69\}}$ Its activation after myocardial injury contributes to an increase in chamber dimension in response to the distending pressure that is thought to be a possible cause of myocyte slippage, which some consider one contributor to chamber remodeling. ${ }^{\{70,71\}}$

The Role of Apoptosis: A working hypothesis for the role of apoptosis in $\mathrm{HF}$ is that progressive LV dysfunction occurs, in part, as a result of ongoing myocyte cell death. ${ }^{\{72\}}$ The importance of this type of cell death in human cardiac remodeling is not yet firmly established, but it has been demonstrated to occur at an increased rate after injury due to ischemia, reperfusion and MI. ${ }^{\{73\}}$ Apoptosis may be an important regulatory mechanism involved in the adaptive response to pressure overload in which initial apoptosis is linked to cardiac hypertrophy. ${ }^{\{74\}}$ Other well-known triggers of apoptosis include cytokines (especially TNF-alpha and the interleukins), oxidative stress and mitochondrial damage. ${ }^{\{75,76\}}$ Recent evidence suggests that myocytes may, in fact, reproduce within the mature heart and may do so at an increased rate in the injured heart. ${ }^{\{7]}$ Clearly, if confirmed, such a process must be considered, as well as apoptosis, in the overall remodeling process. 


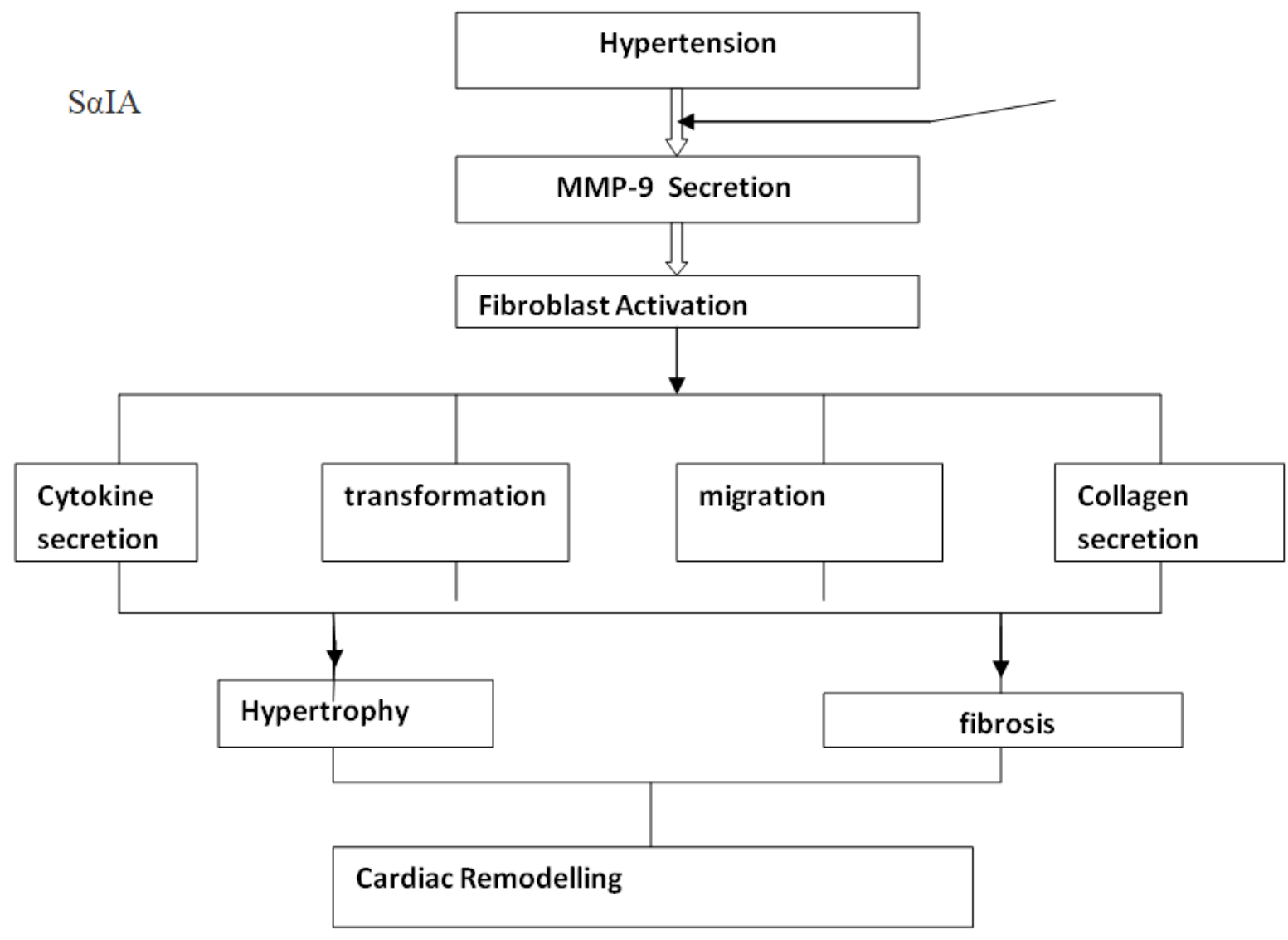

Treatment of Cardiac Remodelling

Many factors influence the time course and extent of remodeling, including the severity of the injury, secondary events (recurrent ischemia or infarction), neurohormonal activation, genetic factors and gene expression, and treatment. Medications may attenuate remodeling; Angiotensin-converting enzyme (ACE) inhibitors have been consistently shown to decrease remodeling in animal models or transmural infarction and chronic pressure overload. Clinical trials have shown that ACE inhibitor therapy after myocardial infarction leads to improved myocardial performance, improved ejection fraction, and decreased mortality compared to patients treated with placebo. Likewise, inhibition of aldosterone, either directly or indirectly, leads to improvement in remodeling. ${ }^{\{78\}}$ Carvedilol, a 3rd generation beta blocker, may actually reverse the remodeling process by reducing left ventricular volumes and improving systolic function. ${ }^{[79,80\}}$ Early correction of congenital heart defects, if appropriate, may prevent remodeling, as will treatment of chronic hypertension or valvular heart disease. Often, reverse remodeling, or improvement in left ventricular function, will also be seen. Diuretics have been used in the treatment of patients with HF since 1919, with the discovery of the diuretic trait of mercury. Currently, loop diuretics, thiazide diuretics, and aldosterone antagonists are commonly used in patients with HF to remove excess volume and relieve symptoms. ${ }^{\{81\}}$

\section{CONCLUSION}

ACE inhibitors, ARB Blockers, Beta blockers is the most effective to treat cardiac remodeling. Scientist has discovered new medicines for cardiac remodeling are Diuretics, Anti- diabetic drugs, Insulin sensitizers drugs. These drugs are gives faster relief in cardiac remodelling.

\section{REFERENCES}

[1] Hockman JS, Bulkley BH. Expansion of acute myocardial infarction: an experimental study. Circulation. 1982;65(7):1446-50.

[2] Mihl, C.; Dassen, W. R. M.; Kuipers, H. (2008). "Cardiac remodelling: Concentric versus eccentric hypertrophy in strength and endurance athletes". Netherlands Heart Journal. 16(4): 129-33. doi:10.1007/BF03086131. PMC 2300466. PMID 18427637.

[3] Ventricular + remodeling at the US National Library of Medicine Medical Subject Headings (MeSH).

[4] Yu, Cheuk-Man; Bleeker, Gabe B.; Fung, Jeffrey Wing-Hong; Schalij, Martin J.; Zhang, Qing; Wall, Ernst E. van der; Chan, Yat-Sun; Kong, Shun-Ling; Bax, Jeroen J. (2005-09-13).

[5] Ypenburg, Claudia; Bommel, Rutger J. van; Borleffs, C. Jan Willem; Bleeker, Gabe B.; Boersma, Eric; Schalij, Martin J.; Bax, Jeroen J. (2009). "Long-Term Prognosis After Cardiac Resynchronization Therapy Is Related to the Extent of Left Ventricular Reverse Remodeling at Midterm Follow-Up". Journal of the American College of Cardiology. 53 (6): 483-90. doi:10.1016/j.jacc.2008.10.032.

[6] Saavedra, W.Federico; Tunin, Richard S; Paolocci, Nazareno; Mishima, Takayuki; Suzuki, George; Emala, Charles W; Chaudhry, Pervaiz A; Anagnostopoulos, Petros; Gupta, Ramesh C (2002). 
"Reverse remodeling and enhanced adrenergic reserve from passive external support in experimental dilated heart failure". Journal of the American College of Cardiology. 39 (12): 2069-76. doi:10.1016/s0735-1097(02)01890-9.

[7] Levine B, Kalman J ,Fillit HM, Packer M, Elevated circulating leval of tumor necrosis factor in severe chronic heart failure, $\mathrm{N}$ Engl J med 1990; 323:236-41.

[8] . Dhalla NS, Dent MR, Tappia PS, et al. Subcellular remodeling as a viable target for the treatment of congestive heart failure. J Cardiovasc PharmacolTherapeut2006;11:31-45.

[9] Cohn JN, Ferrari R, Sharpe N. Cardiac remodelingconcepts and clinical implications: a consensus paper from an international forum on cardiac remodeling. Behalf of an International Forum on Cardiac Remodeling. J Am Coll Cardiol2000;35:569-82.

[10] Tan LB, Jalil JE, Pick R, et al. Cardiac myocyte necrosis induced by angiotensin II. Circ Res 1991;69:1185-95

[11] . Sharov VG, Sabbah HN, Shimoyama H, et al. Evidence of cardiocyte apoptosis in myocardium of dogs with chronic heart failure. Am J Pathol1996;148:141-9

[12] Teiger E, Dam TV, Richard L, et al. Apoptosis in pressure overload - induced heart hypertrophy in the rat. J Clin Invest 1996;97:2891-7.

[13] Olivetti G, Abbi R, Quaini F, et al. Apoptosis in the failing human heart. N Engl J Med 1997;336:113141

[14] Villarreal FJ, Kim NN, Ungab GD, et al. Identification of functional angiotensin II receptors on rat cardiac fibroblastos. Circulation 1993;88:2849-61.

[15] Anderson KR, Sutton MG, Lie JT. Histopathological types of cardiac fibrosis in myocardial disease. J Pathol1978;128:79-85

[16] Katz, Daniel H.; Beussink, Lauren; Sauer, Andrew J.; Freed, Benjamin H.; Burke, Michael A.; Shah, Sanjiv J. (2013). "Prevalence, Clinical Characteristics, and Outcomes Associated with Eccentric Versus Concentric Left Ventricular Hypertrophy in Heart Failure with Preserved Ejection Fraction". The American Journal of Cardiology. 112 (8): 1158-64. doi:10.1016/j.amjcard.2013.05.061. PMC 3788852. PMID 23810323

[17] Levine B, Kalman J ,Fillit HM, Packer M, Elevated circulating leval of tumor necrosis factor in severe chronic heart failure, $\mathrm{N}$ Engl J med 1990; 323:236-41.

[18] . Jugdutt B, ed. In: Aging and Heart Failure. Springer Science + Business Media, New York, 2014:1-475.

[19] Levine B, Kalman J ,Fillit HM, Packer M, Elevated circulating leval of tumor necrosis factor in severe chronic heart failure, $\mathrm{N}$ Engl J med 1990; 323:236-41.

[20] Hedayat M, Mahmaudi MJ, Rose NR, Reznei N, proinflammatory cytokinins in heart failure: double enged swords , heart fail rev. 2010 ; 15:543-62

[21] Hill JA, olson EN, cardiac plasticity, N Engl J MED 2008:358;1370.

[22] Opie LH, commerford PJ, Gresh BJ, plefferMA , controversies in ventricular remodeling lancet2006:367;356.

[23] Hill JA, olson EN, cardiac plasticity, N Engl J MED 2008:358; 1370
[24] Cohn JN, Ferrari R, Sharpe N. Cardiac remodelingconcepts and clinical implications: a consensus paper from an international forum on cardiac remodeling. Behalf of an International Forum on Cardiac Remodeling. J Am Coll Cardiol. 2000;35(3):569-82.

[25] Anand IS, Florea VG, Solomon SD, Konstam MA, Udelson JE. Noninvasive assessment of left ventricular remodeling: concepts, techniques and implications for clinical trials. J Card Fail 2002;8(6 Suppl):S452-64.

[26] Zornoff LA, Paiva SA, Duarte DR, Spadaro J. Ventricular remodeling after myocardial infarction: concepts and clinical implications. Arq Bras Cardiol. 2009;92(2):157-64.

[27] Expert Group on Biomarkers. Biomarkers in cardiology--part 1--in heart failure and specific cardiomyopathies. Arq Bras Cardiol. 2014;103(6):451-9.

[28] Swynghedauw B. Phenotypic plasticity of adult myocardium: molecular mechanisms. J Exp Biol. 2006;209(Pt 12):2320-7.

[29] Haider TA,Peterson LR, Evaluation of diastole in an obseyoung women: mitral valve inflow Doppler vs. mitral annular tissue, doppler imaging $\mathrm{J}$ cardiometabsyndr 2006:1 74-5.

[30] AnversaP, Olivetti G, capasso JM . cellular basis of ventricular remodeling after myocardial infraction. Am cardiol1991 ; 68:7D-16D.

[31] RumerbergJA (1993) Nonparallel changes in global left ventricular chamber volume and muscle mass during the first year after transmural myocardial infarction in humans. J Am Coll Cardiol 21:673-682.

[32] Rumberger JA (1994) Ventricular dilation and remodeling after myocardial infarction. Mayo Clinic Proc 69:664-674.

[33] Grossman W, Jones D, Mclaurin L.D (1975) Wall stress and patterns of hypertrophy in the human left ventricle. J Clin Invest 56:56-64.

[34] Cohn J.N , Levine T.B, (1984) Plasma norepinephrine as a guide to prognosis in patients with chronic congestive heart failure. N Engl J Med 311:819-823.

[35] Chidsev C, Braunwald E (1963) Myocardial norepinephrine concentrations in man. $\mathrm{N}$ Engl J Med 269:653-658.

[36] Benedict C, Johnstine D.E et.al (1990) Comparison of neuroendocrine activation in patients with left ventricular dysfunction with and without congestive heart failure. Circulation 82:1724-1729.

[37] Levine B, Kalman J (1990) Elevated circulating levels of tumor necrosis factor in severe heart failure. N Engl J Med 323:236-241.

[38] Torre amione G, Oral $\mathrm{H}$ et.al (1996) Proinflammatory cytokine levels in patients with depressed left ventricular ejection fraction: a report from the Studies of Left Ventricular Dysfunction (SOLVD). J Am Coll Cardiol 27:1201-1206.

[39] Mccluer S, Carunana L, et.al (1998) Cohort study of plasma natriuretic peptides for identifying left ventricular systolic dysfunction in primary care. BMJ 317:516-519.

[40] Chidsey C, Braunwald E et.al (1963) Myocardial norepinephrine concentrations in man. $\mathrm{N}$ Engl $\mathrm{J}$ Med 269:653-658. 
[41] Levine B , Kalman J et.al(1990) Elevated circulating levels of tumor necrosis factor in severe heart failure. N Engl J Med 323:236-241.

[42] Cohn J.N, Levine T.B et.al (1984) Plasma norepinephrine as a guide to prognosis in patients with chronic congestive heart failure. N Engl J Med 311:819-823.

[43] Cohn J.N, Levine T.B et.al (1984) Plasma norepinephrine as a guide to prognosis in patients with chronic congestive heart failure. N Engl J Med 311:819-823.

[44] Francis G.S, Benedict C et.al(1990) Comparison of neuroendocrine activation in patients with left ventricular dysfunction with and without congestive heart failure. Circulation 82:1724-1729.

[45] Vantrimpont P, Roulear J.L et.al (1998) Two-year course and significance of neurohumoral activation in the Survival and Ventricular Enlargement (SAVE) study. Eur Heart J 19:1552-1563.

[46] Francis G.S, Benedict C et.al (1990) Comparison of neuroendocrine activation in patients with left ventricular dysfunction with and without congestive heart failure. Circulation 82:1724-1729.

[47] 47.Vantrimpont P, Rouleae J.L et.al (1998) Two-year course and significance of neurohumoral activation in the Survival and Ventricular Enlargement (SAVE) study. Eur Heart J 19:1552-1563.

[48] SadoshimaJ,Izumo S et.al(1993) Molecular characterization of angiotensin II-induced hypertrophy of cardiac myocytes and hyperplasia of cardiac fibroblasts. Critical role of the AT1 receptor subtype. Circ Res 73:413-423.

[49] Sadoshima J, xu Y ET.AL (1993) Autocrine release of angiotensin II mediates stretch-induced hypertrophy of cardiac myocytes in vivo. Cell 75:977-984.

[50] Weber K.T, Brilla C.G et.al (1991) Pathological hypertrophy and the cardiac interstitium: fibrosis and the renin-angiotensin-aldosterone system. Circulation 83:1849-1865.

[51] Ollivier J-P, Bouchet VA. Prospects for cardioreparation. Am J Cardiol1992;70:27-36C.

[52] Brilla C.G, ZHOU G et.al (1994) Collagen metabolism in cultured adult rat cardiac fibroblasts: response to angiotensin II and aldosterone. J Mol Cell Immunol 26:809-820.

[53] Sheehan J.P, Seelig M.S et.al (1984) Interactions of magnesium and potassium in the pathogenesis of cardiovascular disease. Magnesium 3:301-314.

[54] McmurrayJ.J, Ray S.G et.al (1992) Plasma endothelin in chronic heart failure.Circulation 85:1374-1379.

[55] Kiowski W, SutschG, et.al(1995) Evidence for endothelin-1-mediated vasoconstriction in severe chronic heart failure. Lancet 346:732-736.

[56] Mulder P, Richaed V et.al(1998) Selective $\mathrm{ET}_{\mathrm{A}}$ blockade prevents left ventricular remodeling and deterioration of cardiac function in experimental models of heart failure. Circ Res 39:600-608.

[57] Mumurray J, Abdullah I et.al (1991) Increased concentrations of tumour necrosis factor in cachectic patients with severe chronic heart failure. Br Heart J 66:356-358.
[58] Torre amione G, Kapadia s (1996) Proinflammatory cytokine levels in patients with depressed left ventricular ejection fraction: a report from the Studies of Left Ventricular Dysfunction (SOLVD). J Am Coll Cardiol 27:1201-1206.

[59] BOZKURT B, Kribbs S.B et.al (1998) Pathophysiologically relevant concentrations of tumor necrosis factor-alpha promote progressive left ventricular dysfunction and remodeling in rats. Circulation 97:1382-1391.

[60] Ferrari R, CECONI C et.al(1991) The occurrence of oxidative stress during reperfusion in experimental animals and men. Cardiovasc Drug Ther 5:277-288.

[61] Agnoletti L, COMINI L et.al(1998) Oxidative stress during myocardial ischemia and heart failure. Eur Heart J 19(Suppl B):S138-S141.

[62] PolunovskyV.A ,WENdt C.H et.al (1994) Induction of endothelial cell apoptosis by TNF alpha modulation by inhibitors of protein synthesis. Exp Cell Res 214:584-594.

[63] Hermann C, Zeiher A.M et.al (1997) Sheer stress inhibits $\mathrm{H}_{2} \mathrm{O}_{2}$-induced apoptosis of human endothelial cells by modulation of the glutathione redox cycle and nitric oxide synthase. ArteriosclerThromVasc Biol 17:3588-3592.

[64] ANversa P, Olivetti G et.al (1991) Cellular basis of ventricular remodeling after myocardial infarction. Am J Cardiol 68:7D-16D.

[65] Francis G,S,Mcdonald K.M et.al (1992) Left ventricular hypertrophy: an initial response to myocardial injury. Am J Cardiol 69:3G-6G.

[66] Dhalla NS, Kaura D, Liu X, Beamish RE. Mechanisms of subcellular remodeling in postinfarct heart failure. In: Konstam M, editor. Myocardial Ischemia: Mechanisms, Reperfusion, Protection. Birkhauser Verlag Basel: Basel, Switzerland 1996:463-77.

[67] Van krimpen C, Smits J.F.M et.al (1991) DNA synthesis in the noninfarcted cardiac interstitium after left coronary artery ligation in the rat: effect of captopril. J Mol Cell Cardiol 23:1245-1253.

[68] Volders P.G.A, Willems I.E.M.G et.al (1993) Interstitial collagen is increased in the noninfarcted human myocardium after myocardial infarction. $\mathbf{J}$ Mol Cell Cardiol 25:1317-1323.

[69] Tyagi S.C, MatsubaraL. Et.al (1993) Direct extraction and estimation of collagenase(s) activity by zymograph in microquantities of rat myocardium and uterus. Clin Biochem 26:191-198.

[70] Cleutjens J.P.M, kanadaka J.C et,al(1995) Regulation of collagen degradation in the rat myocardium after infarction. J Mol Cell Cardiol 27:1281-1292.

[71] Anversa P, Olivetti G et.al (1991) Cellular basis of ventricular remodeling after myocardial infarction. Am J Cardiol 68:7D-16D.

[72] Olivetti G, Capasso J.M et.al (1990) Side-to-side slippage of myocytes in ventricular wall remodeling acutely after myocardial infarction in rats. Circ Res 67:23-34.

[73] Sharov V.G, Sabbah H.N et.al(1996) Evidence of cardiocyte apoptosis in myocardium of dogs with chronic heart failure. Am J Pathol 148:141-149.

[74] Abbi R, Quanin f et.al(1997) Apoptosis in the failing human heart. N Engl J Med 336:1131-1141. 
[75] Teiger E, Dam t,v et.al (1996) Apoptosis in pressure overload-induced heart hypertrophy in the rat. J Clin Invest 97:2891-2897.

[76] Ferrari R, Agnoletti L, et.al (1998) Oxidative stress during myocardial ischemia and heart failure. Eur Heart J 19(Suppl B):S138-S141.

[77] Delong M.L (1998) Apoptosis: a modulator of cellular homeostasis and disease states. Ann NY Acad Sci 842:82-90.

[78] Kajstura J, Leri A et.al (1998) Myocyte proliferation in end stage cardiac failure in humans. Proc Natl Acad Sci 95:8801-8805.

[79] Pitt, Bertram; Remme, Willem; Zannad, Faiez; Neaton, James; Martinez, Felipe; Roniker, Barbara; Bittman, Richard; Hurley, Steve; Kleiman, Jay;
Gatlin, Marjorie (2003). "Eplerenone, a Selective Aldosterone Blocker, in Patients with Left Ventricular Dysfunction after Myocardial Infarction". New England Journal of Medicine. 348 (14): 1309-21.

[80] Khattar, R. S. (2003). "Effects of ACE-inhibitors and beta-blockers on left ventricular remodeling in chronic heart failure". Minerva cardioangiologica. 51 (2): 143-54.

[81] Reis Filho JR, Cardoso JN, Cardoso CM, PereiraBarretto AC (2015). "Reverse Cardiac Remodeling: A Marker of Better Prognosis in Heart Failure". ArquivosBrasileiros de Cardiologia. 104 (6): 502-06.

[82] Vogl A. The discovery of the organic mercurial diuretics. Am Heart J. 1950;39:881-883.

Cite article as: VishwadeepakKimothi, Rahul Singh Dhariyal, Sanjay Singh. A Review On Cardiac Remodelling. Res Pharm Healt Sci.2019;5(2):135-141., doi: https://doi.org/10.32463/rphs.2019.v05i02.03 